\title{
DESCRIÇÃO DE CINCO ESPÉCIES NOVAS DE BAHITA OMAN (HOMOPTERA, CICADELLIDAE, DELTOCEPHALINAE) ${ }^{1}$
}

\author{
Keti Maria Rocha Zanol $^{2}$
}

\begin{abstract}
DESCRIPTION OF FIVE NEW SPECIES OF BAHITA OMAN (HOMOPTERA, Cicadellidae, Deltocephalinal). Five new species of Bahita Oman, 1936, from Brazil, are described: Bahita fenica, B. antonina, B. aguasina, B. variabilis and $B$. joseana.
\end{abstract}

KEY WORDS. Homoptera, Cicadellidae, Deltocephalinae, Bahita

Neste trabalho são descritas cinco espécies novas do Brasil: Bahita fenica sp.n., B. antonina sp.n., B. aguasina sp.n., B. variabilis sp.n. e B. joseana sp.n..

O material-tipo está depositado na Coleção de Entomologia Pe J.S. Moure, Curitiba, Paraná (DZUP), Museu de Zoologia da USP, São Paulo, São Paulo (MZSP), Museu Nacional, Rio de Janeiro, Rio de Janeiro (MNRJ), Museu de História Natural Capão da Imbuia, Curitiba, Paraná (MHNC) e The Natural History Museum, Londres (BMNH).

\section{Bahita fenica sp.n}

Figs 1-8

Comprimento total (em milímetros). Macho/Fêmea: 5,15/5,20.

Cabeça. Coroa de comprimento uniforme; coloração marrom; região frontal e uma estreita faixa junto ao pronoto,amarelas; região discal marrom-avermelhada. Margem anterior estriada. Região frontal voltada para cima; lisa (com leves estrias transversas). Região discal lisa. Sutura coronal ultrapassando a metade do comprimento da coroa. Ocelos na margem anterior. Distância ocelo-ocular menor que o diâmetro dos ocelos. Face marrom; frontoclípeo com arcos laterais e duas faixas, paralelas, próximas aos ocelos, castanho-amarelados. Sutura frontoclipeal estendendo-se além dos ocelos. Sutura transclipeal arqueada. Anteclípeo de lados paralelos, plano.

Pronoto marrom com áreas amarelas; mais estreito que a cabeça com superfície lisa e margens laterais carenadas. Escutelo marrom.

Tégminas com duas células anteapicais, a externa alcançando a célula apical; veia transversa s presente. Clavo com veia extranumerária entre a $1 \mathrm{~A}$ e a sutura claval. Apêndice longo, alcançando a M3+4. Coloração marrom-clara, semitransparente; veias margeadas de marrom; células com manchas, longitudinais, marrons.

1) Contribuição número 948 do Departamento de Zoologia, Universidade Federal do Paraná.

2) Departamento de Zoologia, Universidade Federal do Paraná. Caixa Postal 19020, 81531-990 Curitiba, Paraná, Brasil. Bolsista do CNPq. 

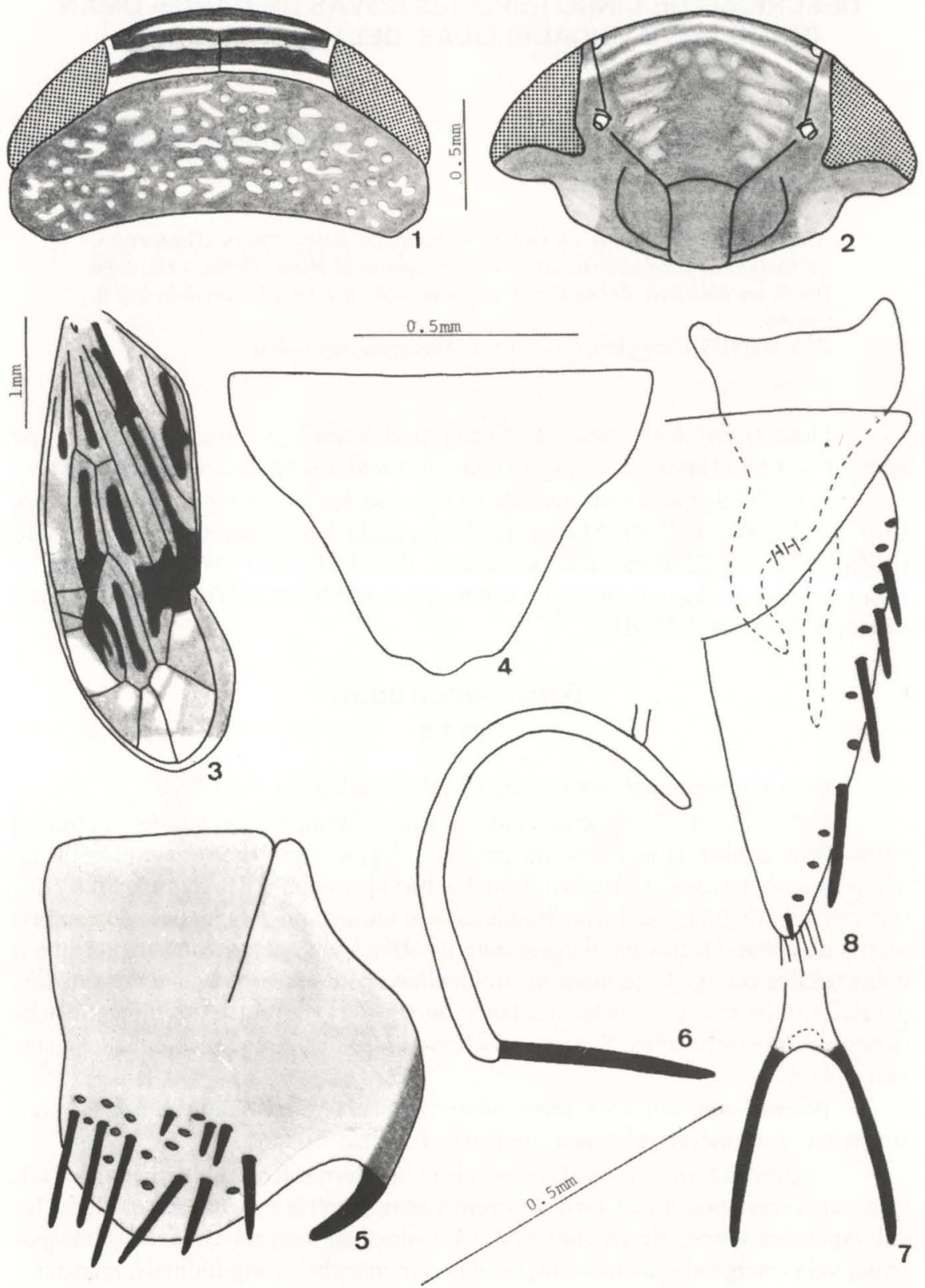

Figs 1-8. Bahita fenica sp.n.., holótipo. (1) Cabeça e pronoto, dorsal; (2) face; (3) tégmina; (4) placa subgenital da fêmea (parátipo); (5) pigóforo, lateral; (6) edeago, lateral; (7) ápice edeago, ventral; (8) valva genital, placa subgenital e estilo. 
Genitália. Macho. Pigóforo com ápice arredondado; um par de apêndices apicais, curvos, não alcançando o ápice do pigóforo. Valva genital triangular com ângulos arredondados. Placa subgenital triangular com ápice arredondado; margens retas; superfície dorsal com dobra longitudinal esclerotinizada; macrocerdas unisseriadas. Estilos digitiformes; apófise finamente serreada. Edeago curvo com um par de apêndices apicais, retos, divergentes, voltados para cima.

Fêmea. Externamente como o macho. Placa subgenital com margens laterais convergentes; margem posterior sinuosa com pequeno lobo mediano.

Material examinado. Holótipo macho. Brasil, Paraná: Fênix (Reserva Est. ITCF), 29-III-1987, Lev. Ent. Profaupar leg. . Parátipos: Ibidem, 1 fêmea; ibidem, 29-XII-1986, 1 fêmea; ibidem, 01-I-1987, 1 fêmea; ibidem, 31-III-1987, 1 macho; ibidem, 29-XI-1986, 1 macho; ibidem, 04-XI-1986, 1 macho; Guarapuava (Est. Águas Santa Clara), 1 macho, 27-I-1987, Lev. Ent. ProfaupaR leg.; Jundiaí do Sul, Fazenda Monte Verde, 29-XI-1986, Lev. Ent. Profaupar leg., 1 macho; ibidem, 13-X-1986, I macho; ibidem, 20-X-1986, I macho; ibidem, 01-XI-1986, I macho (DZUP).

\section{Bahita antonina sp.n.}

Figs 9-16

\section{Comprimento total (em milímetros). Macho: 4,30.}

Cabeça. Coroa marrom; região frontal e uma estreita faixa transversa, junto ao pronoto, amarelas; região discal marrom-clara. Face marrom; frontoclípeo com arcos laterais e duas faixas tranversas, paralelas, abaixo dos ocelos, castanho-avermelhadas. Genas com áreas castanho-avermelhadas.

Pronoto marrom com áreas arredondadas e de contorno irregular, amarelas. Escutelo marrom com áreas marrom-claras.

Tégminas marrom-claras, semitransparentes; ápice do clavo, margem costal e células com manchas longitudinais, marrons. Venação marrom.

Genitália. Macho. Pigóforo com um par de apêndices apicais, sinuosos, atingindo o ápice do pigóforo.Estilos falciformes. Edeago curvo, com um par de pequenos apêndices apicais, divergentes, unidos na base; em vista lateral, a superfície dorsal, proxima ao gonóporo, truncada.

Fêmea. Desconhecida.

Material examinado. Holótipo macho. BRASIL, Paraná: Antonina (Reserva Sapitanduva), 04-XI-1986, Lev. Ent. ProfAUPAR leg. (DZUP).

\section{Bahita aguasina sp.n.}

Figs 17-27

Comprimento total (em milímetros). Macho/Fêmea. 4,40/4,70.

Cabeça. Coroa amarela; margem anterior e duas faixas transversas, paralelas, sobre o disco, marrons. Face marrom; frontoclípeo com arcos laterais e duas faixas transversas, abaixo dos ocelos, castanho-amarelados. Genas com áreas amareladas. 

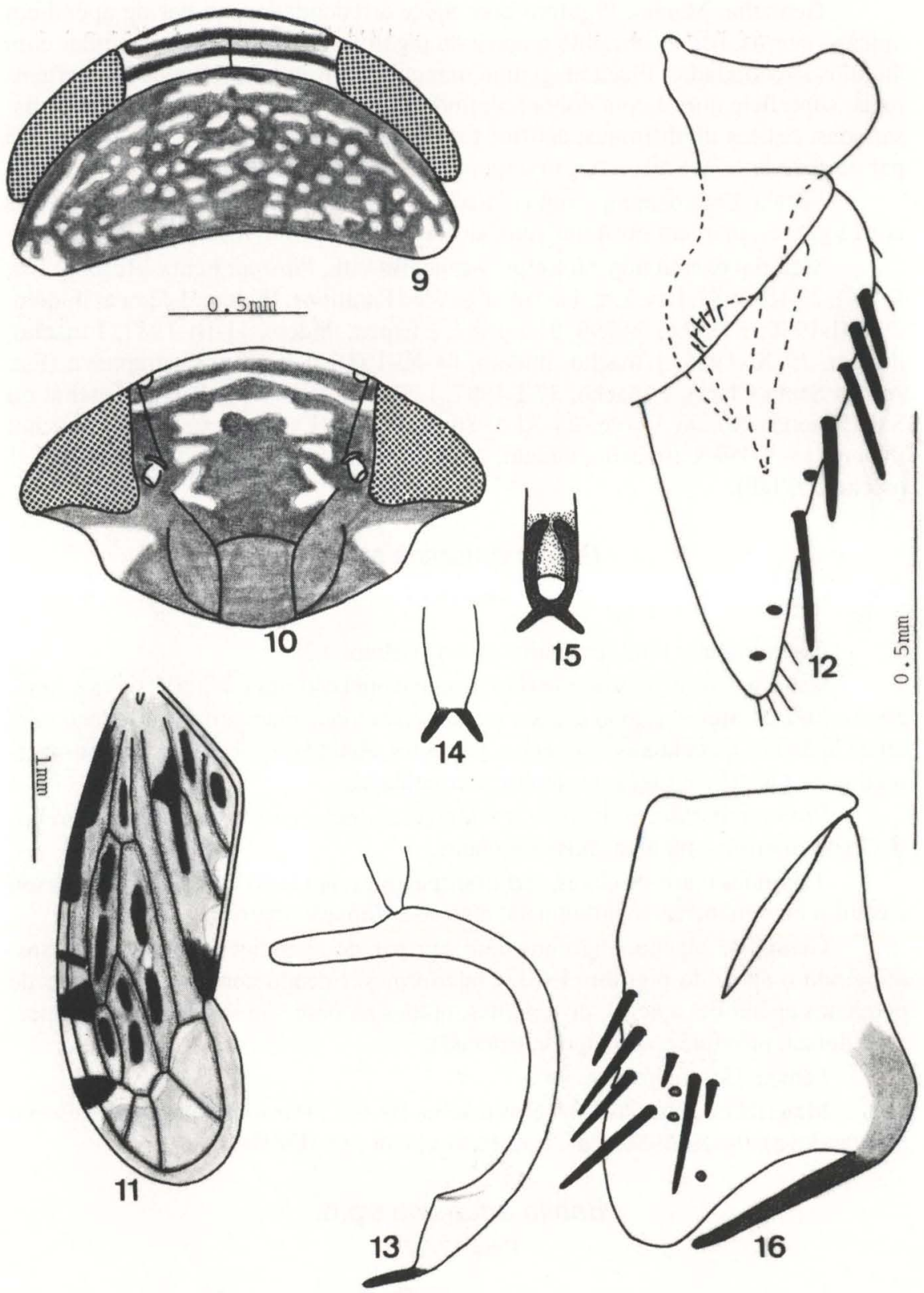

Figs 9-16. Bahita antonina sp.n., holótipo. (9) Cabeça e pronoto, dorsal; (10) face; (11) tégmina; (12) valva genital, placa subgenital e estilo; (13) edeago, lateral; (14) ápice edeago, ventral; (15) ápice edeago, dorsal; (16) pigóforo, lateral. 


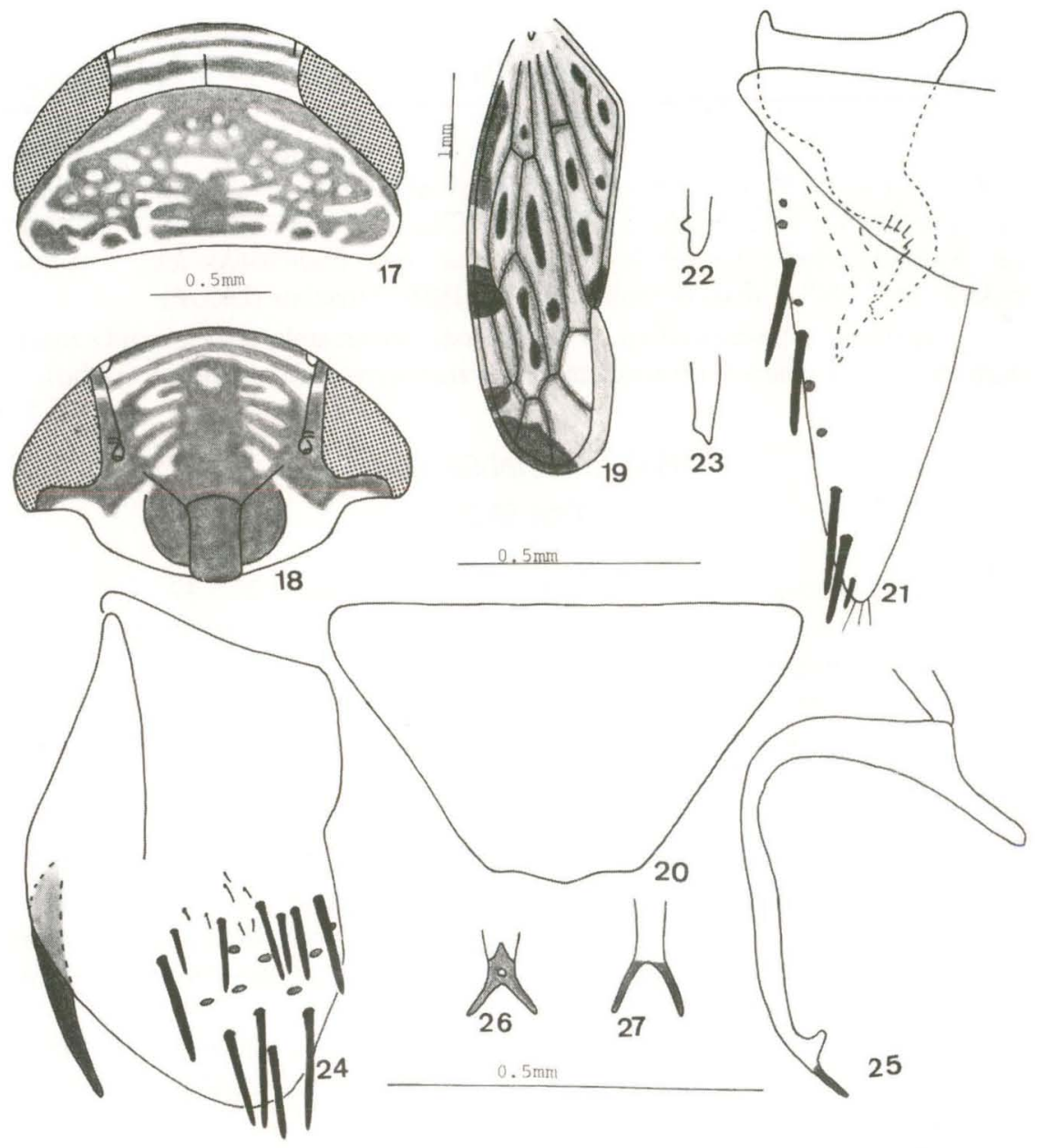

Figs 17-27. Bahita aguasina sp.n., holótipo. (17) Cabeça e pronoto, dorsal; (18) face; (19) tégmina; (20) placa subgenital da fêmea (parátipo); (21) valva genital, placa subgenital e estilo; (22) ápice estilo, lateral; (23) ápice estilo, ventral; (24) pigóforo, lateral; (25) edeago, lateral; (26) ápice edeago, dorsal; (27) ápice edeago, ventral.

Pronoto amarelo com manchas, de contorno irregular, marrons. Escutelo marrom com manchas amarelas.

Tégminas marrom-claras, semitranparentes; veias margeadas de marrom; margem costal com uma mancha quadrangular marrom; ápice do clavo e células com manchas longitudinais, marrons.

Genitália. Macho. Pigóforo com um par de apêndices retos, não alcançando o ápice. Estilos digitiformes; apófise com um pequeno dente apical. Edeago com um par de apêndices apicais, divergentes; ápice, em vista lateral, projetado para dentro e para trás formando dorsalmente, um processo dentiforme, junto ao gonóporo. 
Fêmea. Mais clara que o macho. Placa subgenital com margens laterais convergentes; margem apical sinuosa.

Material examinado. Holótipo macho. BRAsIL, Minas Gerais: Águas Vermelhas, XII-1983, M. Alvarenga leg. Parátipos. ibidem, 2 machos, 1 fêmea; Bahia: Encruzilhada, IX-1975, M. Alvarenga leg., 4 fêmeas, 1 macho; Paraná: Jundiai do Sul (Fazenda Monte Verde), 06-X-1986, Lev. Ent. Profaupar leg., 1 fêmea; ibidem, 29-I-1987, 1 macho; ibidem, 01-XII-1986, 2 machos (DZUP).

Variação intra-específica. A coroa pode ser amarela com a região discal marrom-clara (1 macho). Pronoto amarelo; veia transversa s ausente (1 macho).

\section{Bahita variabilis sp.n.}

Figs 28-36

Comprimento total (em milímetros). Macho/Fêmea: 4,20/5,40

Cabeça. Coroa marrom; região frontal com uma faixa transversa entre as suturas frontoclipeais e outra junto ao pronoto, amarelas. Região discal com uma estreita faixa transversa castanho-avermelhada. Face marrom-clara; frontoclípeo com arcos laterais marrom-claros e duas faixas tranversas, paralelas, próximas aos ocelos, amarelas.

Pronoto marrom com áreas arredondadas amarelas. Escutelo marrom.

Tégminas marrons; ápice e áreas contornando as veias semitransparentes.

Genitália. Macho. Pigóforo sem apêndices; margem ventral levemente esclerotinizada. Estilos falciformes. Edeago com um par de apêndices apicais, curtos, sinuosos, divergentes; superfície dorsal com um par de pequenos processos laterais ao gonóporo.

Fêmea. Mais clara que o macho. Placa subgenital com margens laterais convergentes; margem posterior com uma profunda reentrância e projetada num lobo mediano.

Material examinado. Holótipo macho. BrasiL, Rio de Janeiro: Silva Jardim, III-1974, F.M. Oliveira leg. (DZUP). Parátipos. Bahia: Encruzilhada, IX-1975, M. Alvarenga leg., 2 fêmeas (MNRJ); Rio de Janeiro: Mangaratiba/Muruqui, V-1969, M. Alvarenga leg., B.M. 1971-165 (DZUP); São Paulo: Osasco, XII.1960, M.A. Volcano, 1 macho, 1 fêmea (MZSP); São José do Barreiro (Serra da Bocaina), III-1973, F.M. Oliveira leg., 1 fềmea (DZUP); Paraná: Ponta Grossa, 9/43, coleção F. Justus, 1 fêmea, Quatro Barras (Banhado), 28-II-1970, Becker \& Laroca leg., 1 fêmea, São José dos Pinhais, 19-XI-82, Cavichioli leg., 1 fềmea (DZUP), Rio Branco do Sul, 11-V-83, I. Camargo leg., Museu Paranaense $n^{\circ} 35248$ (MHNC); Santa Catarina: Corupá (Hansa Humboldt, 50W-26S, 100m), I-1930, A. Maller leg., B.M. 1930-286, 2 machos, (near Mafra 50W-26S, 800m), XII.1929, A. Maller B.M. 1930-286, 1 fêmea (BMNH).

Variação intra-específica. Fêmea (de Osasco) com cabeça, pronoto e escutelo amarelos. Frontoclípeo com metade basal amarela. As placas subgenitais das fêmeas variam no tamanho do lobo e profundidade da reentrância. 

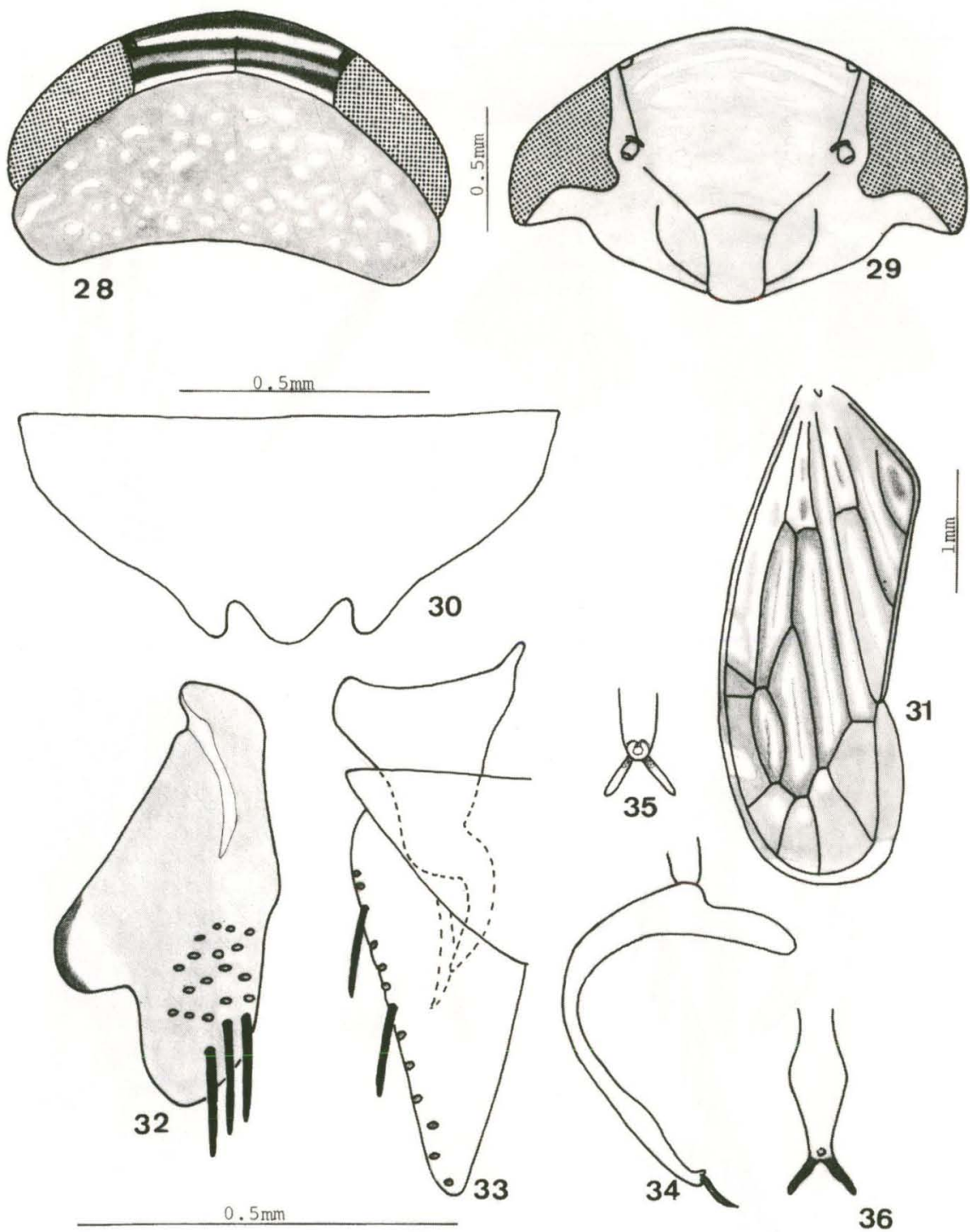

Figs 28-36. Bahita variabilis sp.n., holótipo. (28) Cabeça e pronoto, dorsal; (29) face; (30) placa subgenital da fêmea (parátipo); (31) tégmina; (32) pigóforo, lateral; (33) valva genital, placa subgenital e estilo; (34) edeago, lateral; (35) ápice edeago, dorsal; (36) ápice edeago, ventral. 


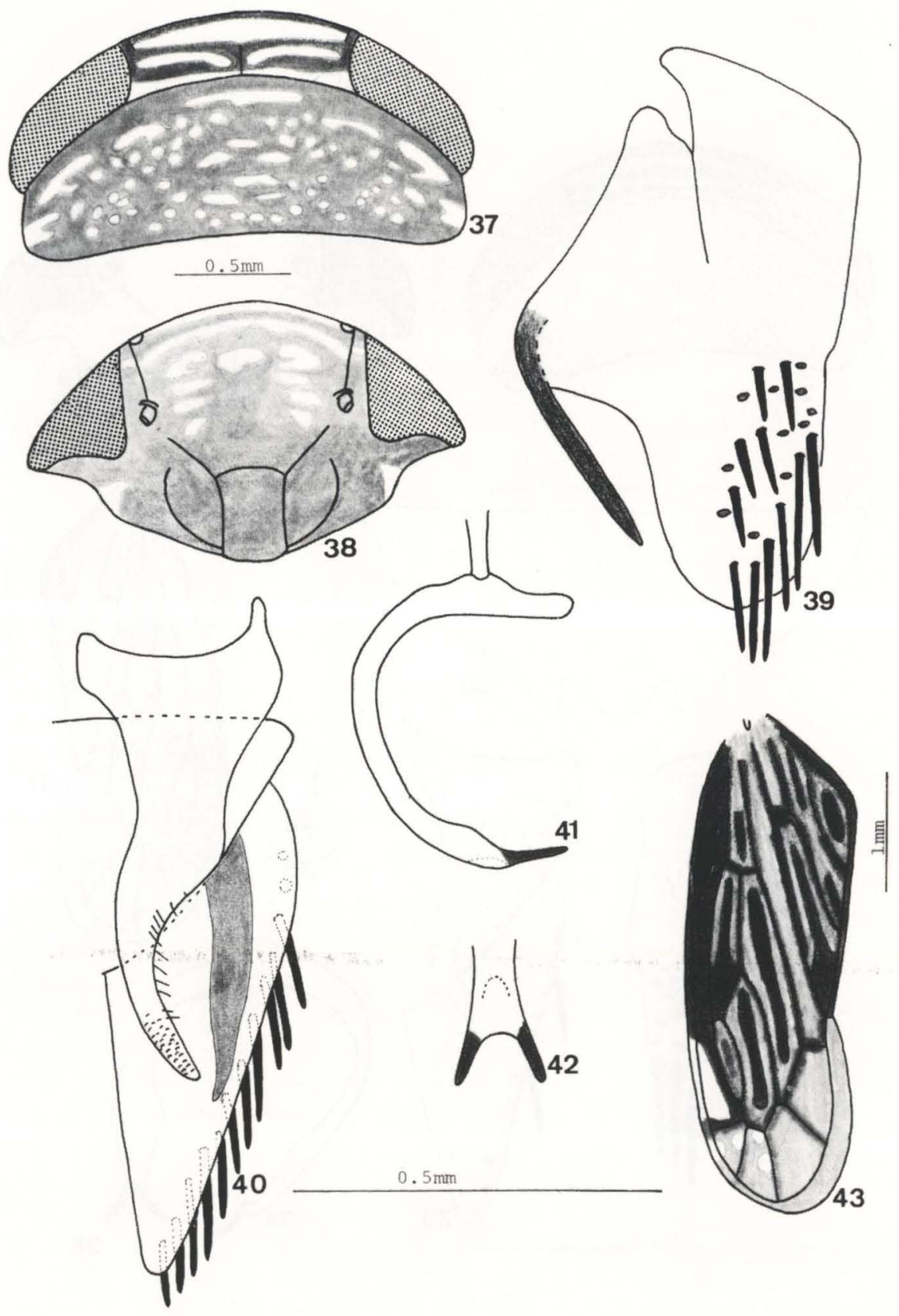

Fig 37-43. Bahita joseana sp.n., holótipo. (37) Cabeça, dorsal; (38) face; (39) pigóforo, lateral; (40) valva genital, placa subgenital e estilo; (41) edeago, lateral; (42) ápice edeago, ventral; (43) tégmina. 


\section{Bahita joseana sp.n.}

Figs $37-43$

Comprimento total (em milímetros). Macho: 4,70.

Cabeça. Coroa marrom-escura; região frontal e uma estreita faixa junto ao pronoto, amarelas; região discal marrom-avermelhada. Face marrom-escura; frontoclipeo com arcos laterais e duas faixas transversas paralelas, abaixo dos ocelos, marrom-avermelhados.

Pronoto marrom-escuro com áreas arredondadas e de contorno irregular, marrom-claras. Escutelo marrom com duas manchas, arredondadas, marrom-avermelhadas.

Tégminas marrom-claras, semitransparentes. Veias de contorno marrom. Margem costal e células com manchas longitudinais, marrons. Célula anteapical externa curta, não alcançando a célula apical; veia transversa s ausente.

Genitália. Macho. Pigóforo com um par de apêndices retos, curtos, não alcançando o ápice do pigóforo. Estilos digitiformes; apófise finamente rugosa; ápice com um pequeno dente dorsal. Edeago com um par de apêndices látero-apicais curtos e divergentes; extremidade apical, em vista dorsal, truncada.

Fêmea. Desconhecida.

Material examinado. Holótipo macho. BRAsil, Paraná: São José dos Pinhais (Ser. Mar, BR 277 Km 54), 02-XII-1986, Lev. Ent. Profaupar leg.. Parátipos. ibidem, 1 macho; ibidem, 30-III-1987, 1 macho, 26-II-1987, 1 macho; ibidem 04-XI-1986 (DZUP).

Variação intra-específica. Um parátipo (04-XI-1986) com pronoto amarelo; a célula anteapical externa, na tégmina direita, é curta e, na tégmina esquerda, longa.

\section{REFERÊNCIAS BIBLIOGRÁFICAS}

LiNNAVUORI, R. 1959. Revision of the neotropical Deltocepha-linae and some related subfamilies (Homoptera). Ann. Zool. Soc. Vanamo 20 (1): 1-370.

LinNavuori, R. \& D.M. DELONG. 1978. Neotropical leafhoppers of the Bahita group (Homoptera: Cicadellidae: Deltocephalinae). A contribution to the taxonomy. Brenesia 14-15: 109-169.

OMAN, P.W. 1936. A generic revision of american Bythoscopinae and south american Jassinae. Univ. Kans. Sci. Bull. 24 (16): 343-420.

Osborn, H. 1923. II. Neotropical Homoptera of the Carnegie Museum. Part 2. Records and descriptions of five new genera and sixty-five new species of the subfamily Jassinae. Ann. Carnegie Mus. 15 (1): 27-79. 